\title{
Tattooing in Hidradenitis Suppurativa
}

\author{
Philippe Guillem ${ }^{\mathrm{a}-\mathrm{c}}$ Nicolas Kluger ${ }^{\mathrm{d}} \mathrm{e}$ \\ ${ }^{a}$ Department of Surgery, Clinique du Val d'Ouest, Ecully, France; ${ }^{b}$ ResoVerneuil, Paris, France; ${ }^{c}$ European

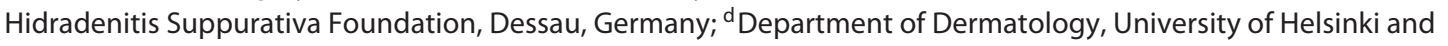 \\ Helsinki University Central Hospital, Helsinki, Finland; " "Tattoo" Consultation, Department of Dermatology, \\ Bichat-Claude Bernard Hospital, Assistance Publique-Hôpitaux de Paris, Paris, France
}

Sir,

We thank Drs. Andersen and Alsing for their interest in our recent paper on tattooing in patients with hidradenitis suppurativa (HS) [1]. A significant increase in body art practices, particularly tattooing, was reported by HS patients [1].

Andersen and Alsing point out that the tattoo prevalence is associated with low educational and socioeconomic status and youth [2] as is evident from Table 1 and the discussion of our paper.

The association between tattoos and lower economic status is well known and has been well studied in the French population [3-5]. Low socioeconomic status may be a confounder as it has also been associated with HS [6]. Our study was based on an anonymous questionnaire [1] but 73/209 (35\%) of the patients volunteered their name allowing us to extract data from their medical records. This sample did not differ from the other respondents in age, mean age at disease occurrence, sex ratio, disease severity and tattoo or body piercing prevalence (data not shown). Tattoo prevalence is higher in young individuals $[3-5,7]$. The mean age of our cohort was 33 years.

Based on the explorative nature of our data we therefore hypothesize about the possible association between HS and body art, and a conservative comparison, fully acknowledging the risk of bias, nevertheless leads us to the hypothesis of higher tattoo prevalence in HS patients.

\section{Key Message}

Patients with hidradenitis suppurativa do have increased tattooing practices.

\section{Statement of Ethics}

The research was conducted ethically in accordance with the World Medical Association Declaration of Helsinki. The study protocol was approved by the institute's ethical committee. 


\section{Conflict of Interest Statement}

P. Guillem received honoraria from AbbVie and Novartis as a consultant and provided lectures for AbbVie, Brothier, Cicaplus, Coloplast, Inresa and Novartis.

N. Kluger served as a consultant to AbbVie and has received research funding from $\mathrm{AbbVie}$ and speaker fees from AbbVie in 2015-2016.

\section{References}

1 Guillem P, Raynal H, Wendling A, Kluger N. Hidradenitis suppurativa influences tattooing practice in women. Dermatology. 2020; 236(5):445-51.

2 Kjærsgaard Andersen R, Alsing KK. Reply to "Hidradenitis suppurativa influences tattooing practice in women." Dermatology. 2020; 236(5):452-3.

\section{Author Contributions}

P.G. and N.K.: design of the work, acquisition, analysis and interpretation of the data, drafting of the work.
3 Fourquet J. Les Français et les tatouages. Paris: IFOP; 2010.

4 Fourquet J, Dubrulle JP. Les Français et le tatouage. Paris: IFOP; 2016.

5 Fourquet J, Dubrulle JP. La pratique du tatouage en France, au Royaume Uni et aux Etats-Unis. Paris: IFOP; 2018.
6 Deckers IE, Janse IC, van der Zee HH, Nijsten T, Boer J, Horváth B, et al. Hidradenitis suppurativa (HS) is associated with low socioeconomic status (SES): a cross-sectional reference study. J Am Acad Dermatol. 2016 Oct; 75(4):755-759.e1.

7 Kluger N, Misery L, Seité S, Taieb C. Tattooing: a national survey in the general population of France. J Am Acad Dermatol. 2019 Aug;81(2):607-10. 